ARTICLE

\title{
A metal-supported single-atom catalytic site enables carbon dioxide hydrogenation
}

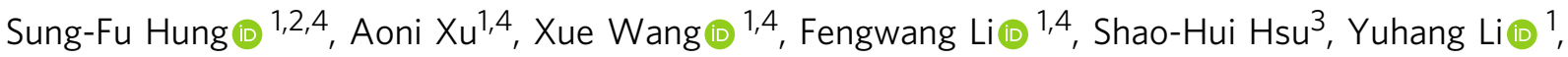 \\ Joshua Wicks (1) ${ }^{1}$, Eduardo González Cervantes ${ }^{1}$, Armin Sedighian Rasouli ${ }^{1}$, Yuguang C. Li ${ }^{1}$, Mingchuan Luo (1) ${ }^{1}$, \\ Dae-Hyun Nam¹, Ning Wang1, Tao Peng (iD 1, Yu Yan', Geonhui Lee (iD ${ }^{1}$ \& Edward H. Sargent (i) ${ }^{1 凶}$
}

Nitrogen-doped graphene-supported single atoms convert $\mathrm{CO}_{2}$ to $\mathrm{CO}$, but fail to provide further hydrogenation to methane - a finding attributable to the weak adsorption of $\mathrm{CO}$ intermediates. To regulate the adsorption energy, here we investigate the metal-supported single atoms to enable $\mathrm{CO}_{2}$ hydrogenation. We find a copper-supported iron-single-atom catalyst producing a high-rate methane. Density functional theory calculations and in-situ Raman spectroscopy show that the iron atoms attract surrounding intermediates and carry out hydrogenation to generate methane. The catalyst is realized by assembling iron phthalocyanine on the copper surface, followed by in-situ formation of single iron atoms during electrocatalysis, identified using operando X-ray absorption spectroscopy. The coppersupported iron-single-atom catalyst exhibits a $\mathrm{CO}_{2}$-to-methane Faradaic efficiency of $64 \%$ and a partial current density of $128 \mathrm{~mA} \mathrm{~cm}{ }^{-2}$, while the nitrogen-doped graphene-supported one produces only $\mathrm{CO}$. The activity is 32 times higher than a pristine copper under the same conditions of electrolyte and bias.

\footnotetext{
${ }^{1}$ Department of Electrical and Computer Engineering, University of Toronto, Toronto, ON, Canada. ${ }^{2}$ Department of Applied Chemistry, National Yang Ming Chiao Tung University, Hsinchu 300, Taiwan. ${ }^{3}$ Taiwan Semiconductor Research Institute, National Applied Research Laboratories, Hsinchu 300, Taiwan.

${ }^{4}$ These authors contributed equally: Sung-Fu Hung, Aoni Xu, Xue Wang, Fengwang Li. ${ }_{\text {email: ted.sargent@utoronto.ca }}$
} 
$\mathrm{M}$ etal nanostructures supported on host substrates, such as metal oxide, metal, and graphene, are widely used in heterogeneous catalysis ${ }^{1,2}$. The size of metal nanoclusters is a prime determinant of the catalytic characteristics of the resultant composite materials.

Recently, the ultimate small-size limit for metal catalystsnitrogen-doped graphene-supported single atoms-has attracted interest for its potential in reducing $\mathrm{O}_{2}$ and $\mathrm{CO}_{2}{ }^{3-7}$. Isolated metal atoms immobilized on nitrogen-doped carbon substrates through metal-nitrogen coordination have shown excellent $\mathrm{O}_{2^{-}}$ reducing activity, comparable to that of platinum catalysts ${ }^{8,9}$, and have also enabled $\mathrm{CO}_{2}$ reduction reaction ( $\mathrm{CO} 2 \mathrm{RR}$ ) instead of the competing hydrogen evolution that is seen in the bulk forms of the same materials ${ }^{10,11}$.

Until now, however, $\mathrm{CO}_{2} \mathrm{RR}$ products from nitrogen-doped graphene-supported single atoms have been limited to CO: the weak binding of ${ }^{*} \mathrm{CO}$ intermediates led to facile release of gaseous $\mathrm{CO}^{12-14}$. We posited here that it would be possible to modulate $\mathrm{CO}_{2} \mathrm{RR}$ selectivity toward hydrocarbons if we could regulate the electronic structure of the single-atom site by altering dramatically the choice of host substrate. In prior studies of metalsupported single atoms, i.e., metals incorporating atomicallydispersed elements ${ }^{11,15}$, DFT calculations have predicted that the binding and activation energies of reaction intermediates on the metal-supported single atoms can be tuned to promote catalytic behavior ${ }^{16,17}$.

We pursued the conversion of $\mathrm{CO}_{2}$ to hydrocarbons-methane in the present work-offering a means to store renewable electricity in the form of chemical fuels ${ }^{18-21}$. Enhancing catalytic activity and improving selectivity remain key goals ${ }^{22-24}$, and, among $\mathrm{CO}_{2} \mathrm{RR}$ products, methane is of interest in light of its established infrastructure for storage, distribution, and utilization. Prior catalysts have exceeded $50 \%$ of the selectivity for methane, but at lower than practical current densities ${ }^{25-27}$, which limits industrial application: indeed, such analyses suggest an initial target selectivity of $60 \%$ combined with current density $>100 \mathrm{~mA} \mathrm{~cm}^{-2} 28,29$.

\section{Results and discussion}

We began by investigating, using DFT calculations, whether $\mathrm{CO}_{2}$ methanation is feasible on atomically-dispersed elements on $\mathrm{Cu}(111)$, the preferred orientation in polycrystalline copper exhibiting the lowest surface energy of all low-index facets of $\mathrm{Cu}$ with an fcc crystal structure (Supplementary Table 1). We first examined, on the single-atom sites, the adsorption energies of ${ }^{*} \mathrm{CO}$ vs. ${ }^{*} \mathrm{H}$ and the hydrogenation energy of ${ }^{*} \mathrm{CO}$ (Fig. 1a). The adsorption of $\mathrm{CO}$ favors $\mathrm{CO}_{2} \mathrm{RR}$, while ${ }^{*} \mathrm{H}$ determines the ease of further reduction to methane $21,22,24$. We found that $\mathrm{Fe}$ single atoms, among a range of transition metals explored, exhibit the strongest ${ }^{*} \mathrm{CO}$ affinity over competing ${ }^{*} \mathrm{H}$, and the lowest hydrogenation energy of $* \mathrm{CO}$, suggesting a tendency for $\mathrm{CO}_{2} \mathrm{RR}$ to products beyond $\mathrm{CO}$. Interestingly, transition elements such as $\mathrm{Co}$ and $\mathrm{Ni}$, show favorable trends for $\mathrm{CO}_{2} \mathrm{RR}$ as well. The selectivity toward methane is higher for $\mathrm{Cu}-\mathrm{NiSA}$ and $\mathrm{Cu}-\mathrm{CoSA}$ (Fig. 1b) compared to pristine $\mathrm{Cu}$, but lower than that when $\mathrm{Fe}$ is used.

With the view that particle size can influence catalytic activityprior reports highlighted that aggregated forms of Fe prefer HER, while the single-atom form adopts $\mathrm{CO}_{2} \mathrm{RR}^{5,10}$-we further examined the effect of Fe domain size, and found that the affinity of ${ }^{*} \mathrm{CO}$ and ${ }^{*} \mathrm{H}$ is dependent on the size of $\mathrm{Fe}$ in the $\mathrm{Cu}$ host. Fe atoms exhibit an increasing ${ }^{*} \mathrm{CO}$ affinity and a decreasing ${ }^{*} \mathrm{H}$ affinity as the $\mathrm{Fe}$ domain size decreases, and they reach the highest affinity for ${ }^{*} \mathrm{CO}$ over ${ }^{*} \mathrm{H}$ on single-site Fe (Fig. 1c). This sizedependent relationship is attributed to the fact that $\mathrm{Fe}$ single atoms redistribute the $d$ orbitals near the Fermi level compared to bulk counterparts (Supplementary Fig. 1), altering their adsorption properties and thus their catalytic selectivity. We compared the $\mathrm{CO}_{2} \mathrm{RR}$ performance of $\mathrm{Fe}$ single-atom catalysts vs. aggregated Fe catalysts (Fig. 1d). Fe nanoparticles on the $\mathrm{Cu}$ surface produce hydrogen, consistent with prior reports ${ }^{10}$. Narrowing the size of Fe to clusters (Supplementary Fig. 2) produces a maximum methane $\mathrm{FE}$ of $39 \%$. Cu-Fe clusters, accordingly, have exhibited a modest selectivity toward methane in a photoelectrochemical system ${ }^{30}$, indicating the size effect on methane selectivity. Only by further reducing the Fe size to the single-atom level do we maximize selectivity toward methane.

In examining the catalyst's density of states by DFT calculations, we found that $\mathrm{Fe}$ single atoms offer $d$ orbitals near the Fermi level (Fig. 2a): such electronic properties have previously been shown to facilitate the adsorption of reaction intermediates ${ }^{31}$. By deconvoluting these $\mathrm{d}$ orbitals, we found that they arise mainly from the $z$ axis character (Fig. $2 \mathrm{~b}$ and Supplementary Fig. 3), resulting in preferred adsorption of ${ }^{*} \mathrm{CO}$ on atop sites of $\mathrm{Fe}$ (Fig. $2 \mathrm{c})^{32}$. In comparison, ${ }^{*} \mathrm{CO}$ binds at the hollow sites of $\mathrm{Cu}$ atoms (Fig. $2 \mathrm{c}$ and Supplementary Fig. 4). The binding of ${ }^{*} \mathrm{CO}$ to atop $\mathrm{Fe}$ is stronger than that to hollow Cu. In Fig. 2d, we find that $* \mathrm{CO}$ transfers from $\mathrm{Cu}$ nearby (bridge sites and atop sites) to atop $\mathrm{Fe}$, indicated by arrowheads, while only $\mathrm{Cu}$ at hollow sites is stabilized at the original sites.

To study product selectivity, we calculated the post-adsorption steps on $\mathrm{Cu}-\mathrm{FeSA}$ : CO hydrogenation and $\mathrm{C}-\mathrm{C}$ coupling. Their energy level determines the branching of $\mathrm{C} 1$ (e.g., $\mathrm{CH}_{4}, \mathrm{CH}_{3} \mathrm{OH}$ ) vs. $\mathrm{C} 2$ (e.g., $\mathrm{C}_{2} \mathrm{H}_{4}, \mathrm{C}_{2} \mathrm{H}_{5} \mathrm{OH}$ ) products ${ }^{21,22,24}$. We found that $\mathrm{C}-\mathrm{C}$ coupling is energetically unfavorable on $\mathrm{Cu}-\mathrm{FeSA}$ (both on $\mathrm{Cu}$ $\mathrm{Cu}$ and $\mathrm{Cu}-\mathrm{Fe}$ sites) compared to on $\mathrm{Cu}$ (Fig. 2e), indicating that * $\mathrm{CO}$ adsorbed on atop Fe sites will not couple with neighboring ${ }^{*} \mathrm{CO}$ on $\mathrm{Cu}$ sites to generate $\mathrm{C} 2$ products. We further investigated the surface CO coverage effect on Cu-FeSA surface, shown in Supplementary Fig. 5. Hydrogenation and coupling reactions are promoted with increasing $\mathrm{CO}$ coverage, in agreement with previous studies ${ }^{23,33,34}$, while $\mathrm{C}_{2}$ will become favored at high coverage. Previous quantum mechanical studies predict that $\mathrm{Au} / \mathrm{Ag}$ supported single atoms favor $\mathrm{C} 1$ products ${ }^{17} .{ }^{*} \mathrm{CO}$ undergoes hydrogenation to form ${ }^{*} \mathrm{COH}$ favorably over ${ }^{*} \mathrm{CHO}$ on the $\mathrm{Fe}$ sites of $\mathrm{Cu}$-FeSA when there is a contribution of solvation (Fig. $2 \mathrm{f}$ and Supplementary Figs. 6, 7), while ${ }^{*} \mathrm{CHO}$ is preferred on pristine $\mathrm{Cu}$ (Supplementary Fig. 8). The overall $\mathrm{CO}_{2}$-to-methane energy diagram for $\mathrm{Cu}-\mathrm{FeSA}$ indicates that the rate determining step is ${ }^{*} \mathrm{CO} \rightarrow{ }^{*} \mathrm{COH}(\Delta \mathrm{E}=0.52 \mathrm{eV}$, Fig. $2 \mathrm{~g})$. Taken together, the DFT calculations suggest that $\mathrm{Cu}-\mathrm{FeSA}$ favors the production of $\mathrm{CH}_{4}$ via a pathway involving the hydrogenation of ${ }^{*} \mathrm{CO}$ to ${ }^{*} \mathrm{COH}$ instead of $\mathrm{C}-\mathrm{C}$ coupling.

We pursued therefore the experimental synthesis of the metalsupported single atoms, a challenge in materials science due to the ease of aggregation of the single sites. We employed a planar complex, iron-phthalocyanine $(\mathrm{FePc})$, as the precursor of the single-atom metal: this, we posited, could separate central Fe ions and minimize the distance between the $\mathrm{Fe}$ ion and the $\mathrm{Cu}$ surface. Because $\mathrm{FePc}$ does not interact with the $\mathrm{Cu}$ surface, $\mathrm{FePc}$ is not directly adsorbed on the $\mathrm{Cu}$ surface (Supplementary Fig. 9); we therefore functionalized the $\mathrm{Cu}$ surface with the aid of 3-mercaptopropionic acid (3-MPA), enabling the thiol end to anchor the $\mathrm{Cu}$ surface and the oxyl end to bond with the central $\mathrm{Fe}$ ions in $\mathrm{FePc}$, forming $\mathrm{Cu}-\mathrm{FePc}$ (inset of Fig. 3a). This approach was designed to avoid FePc stacks that could produce aggregation of $\mathrm{Fe}$, and sought to ensure that $\mathrm{FePc}$ deposited on the $\mathrm{Cu}$ surface. Evidence of this is seen in depth-profiling X-ray photoelectron spectroscopy in Supplementary Fig. 10.

Using X-ray diffraction (XRD), we estimate distance between the $\mathrm{Fe}$ ion and $\mathrm{Cu}$ to be $7.8 \AA$ (diffraction peak at $11.3^{\circ}$ in Fig. 3a), 
a

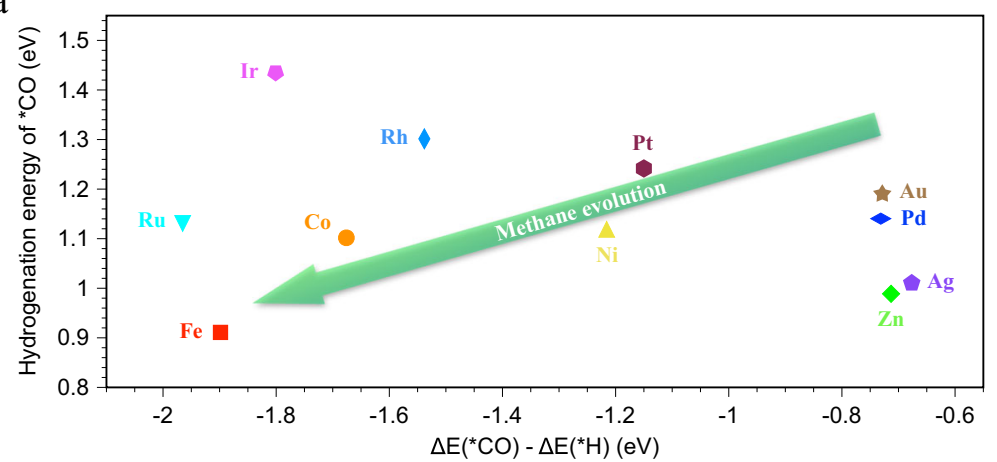

c

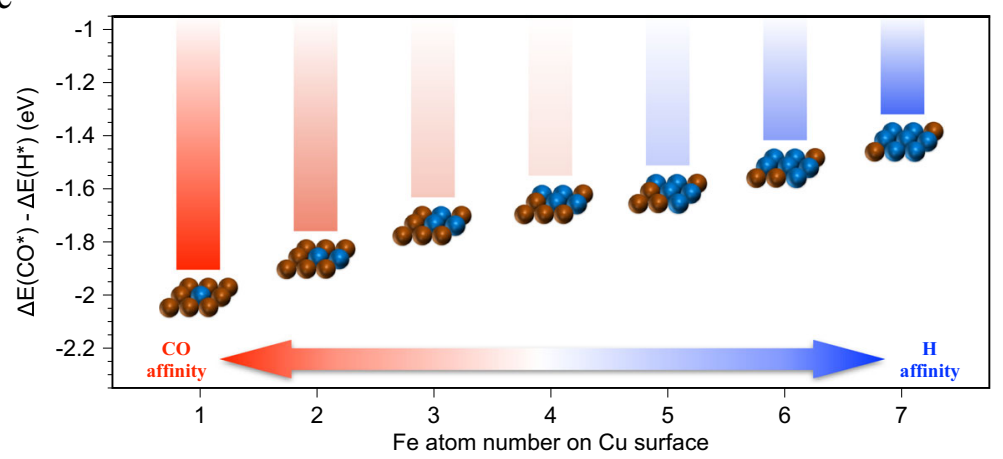

b

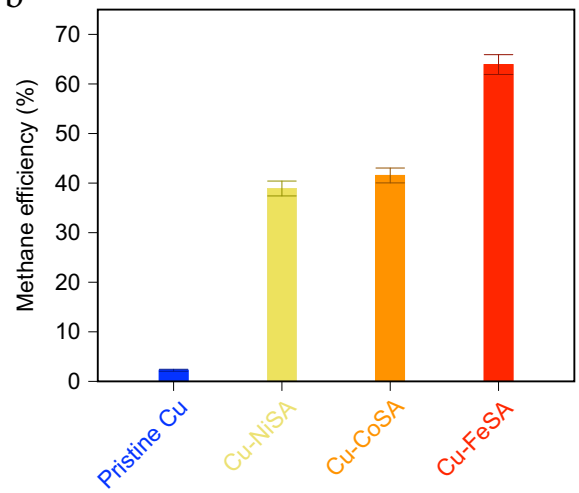

d

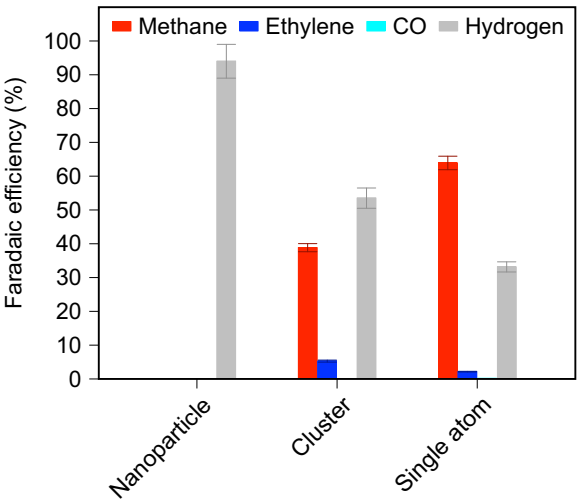

Fig. 1 Calculations and catalytic activities for single-atom-anchored copper. a Comparison of adsorption energy and hydrogenation of ${ }^{\star} \mathrm{CO}$ on various single-atom catalytic sites. b Catalytic methane activities of pristine $\mathrm{Cu}$ vs. various single-atom-anchored copper catalysts for $\mathrm{CO}_{2}$ reduction reaction. c Effect of iron domain sizes in the copper surface on the adsorption energies of ${ }^{*} \mathrm{H}$ and ${ }^{\star} \mathrm{CO}$. $\mathbf{d}$ Catalytic activities of various iron-dispersed copper materials, including nanoparticle, cluster, and single-atom forms. The error bars represent $1 \mathrm{s.d}$. on the basis of three independent samples.

matching the predicted distance Fe $\cdots 3-\mathrm{MPA} \cdots \mathrm{Cu}$. We do not observe diffraction signals related to its stacking in FePc powder at $10^{\circ}, 15.7^{\circ}$, and $16.3^{\circ 35}$. We associate the grazing-incidenceangle XRD in Supplementary Fig. 11 (signal at $11.3^{\circ}$ ) with contributions from surface self-assembling FePc. The rough surface of sputtered copper provides ample adsorption sites for iron phthalocyanine, exhibiting the intensified monolayer XRD signal. We also conduct atomic force microscope studies; the roughness of $\sim 9 \mathrm{~nm}$ on the sputtered copper (Supplementary Fig. 12), while a 9 Angstrom step height, corresponding to the predicted distance $\mathrm{Fe} \cdots 3-\mathrm{MPA} \cdots \mathrm{Cu}$, is observed on the iron-phthalocyaninemodified copper (Supplementary Fig. 13). The $\mathrm{Cu}$ surface becomes smoother following molecular assembly (Supplementary Fig. 14) but keeps a (111) preferred orientation, shown in Fig. 3a (the peak at $43.5^{\circ}$ ). Using X-ray absorption spectroscopy (XAS), we found that the intramolecular coordination environment of the oxyl-bonded FePc remains similar to that of unbound $\mathrm{FePc}$ (Fig. 3b), while the oxidation state of the central Fe increases slightly, a finding we ascribe to the additional coordination of the oxyl bond (Supplementary Fig. 15). We observe additional vacancies in the $3 d$ orbitals of the central Fe atom (Supplementary Fig. 16), which we assign to bonding with the high electronaffinity oxyl end in 3-MPA. Focusing on the bonding environment of surface $\mathrm{Cu}$ (Supplementary Fig. 17), we observe an energy shift to the lower binding energy of the $\mathrm{Cu}$ peak in $\mathrm{Cu}$ $\mathrm{FePc}$, allowing us to identify $\mathrm{Cu}-\mathrm{S}$ functional bonding during 3-MPA surface modification ${ }^{36,37}$. The shoulder at higher binding energies is attributed to the $\mathrm{Cu}-\mathrm{O}$ due to exposure to air prior to XAS measurement. Overall, the XRD and XAS studies suggest the formation of self-assembling $\mathrm{FePc}$ on $\mathrm{Cu}$, without measurable evidence of stacking beyond a monolayer.

We applied a negative bias to enable the Fe-N cleavage and formation of $\mathrm{Cu}-\mathrm{FeSA}$. This provides in-situ synthesis during $\mathrm{CO}_{2} \mathrm{RR}$ : the $\mathrm{FePc}$ reductive demetallation process initiates at potentials as positive as $+0.4 \mathrm{~V}$ vs $\mathrm{RHE}^{38}$, and continues in the potential range ( -0.7 to $-1.3 \mathrm{~V}$ vs $\mathrm{RHE}$ ) of $\mathrm{CO}_{2} \mathrm{RR}$. We found, using in-situ XAS (Fig. 3c), that the Fe-N bond disappears and the $\mathrm{Fe}-\mathrm{Cu}$ metallic bond (a lower coordination intensity compared to pure $\mathrm{Fe}$ metal) emerges during $\mathrm{CO}_{2} \mathrm{RR}^{39}$. Accordingly, the oxidation state also changes from that of a cation to a metallic one, and the electronic state differs from that of pure Fe metal (Fig. 3d and Supplementary Figs. 18-20). The large diameter of the phthalocyanine ring $(15 \AA)$ separates iron ions $(2.52 \AA)$ well $^{40}$, preventing self-aggregation of Fe ions. We further confirmed the $\mathrm{Cu}-\mathrm{Fe}$ bond from structural fitting of the extended X-ray absorption fine structure (EXAFS, Supplementary Fig. 21). We also found, from N 1s XPS (Supplementary Fig. 22), that the peak from $\mathrm{N}-\mathrm{Fe}$ and $\mathrm{N}-\mathrm{C}$ in $\mathrm{FePc}$ drops following electroreduction $^{41,42}$, suggesting the detachment of the phthalocyanine ring from the surface. We also investigated $\mathrm{Cu}$ K-edge XAS from which we found that $\mathrm{Cu}$ keeps its metallic state during $\mathrm{CO}_{2} \mathrm{RR}$ (Supplementary Figs. 23, 24). Using atomic-resolution transmission electron microscopy (Fig. 3e), we observe the dispersion of single $\mathrm{Fe}$ atoms in the $\mathrm{Cu}$ matrix. Single $\mathrm{Fe}$ atoms appear as bright spots, the result of their causing a more scattered electron beam received by the high-angle annular detector.

The distribution of $\mathrm{Fe}$ atoms in the as-formed $\mathrm{Cu}-\mathrm{FeSA}$ is uniform, and we did not see evidence of an aggregated form of 
a

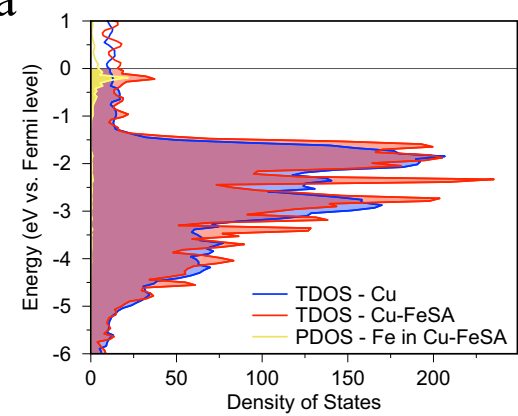

b

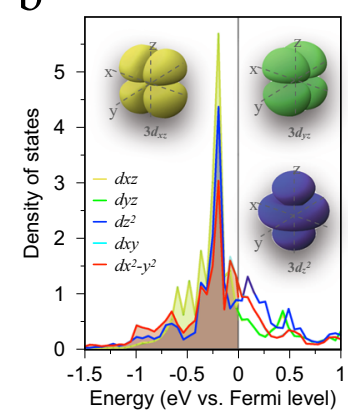

C

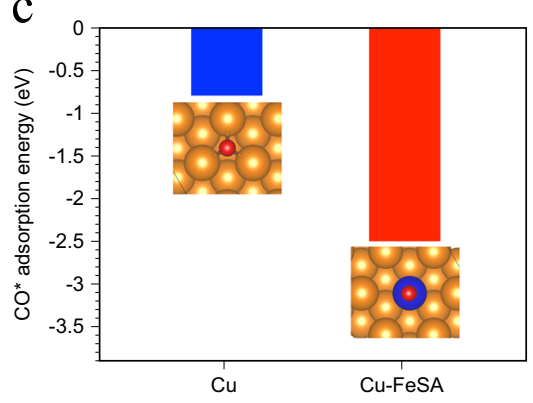

d

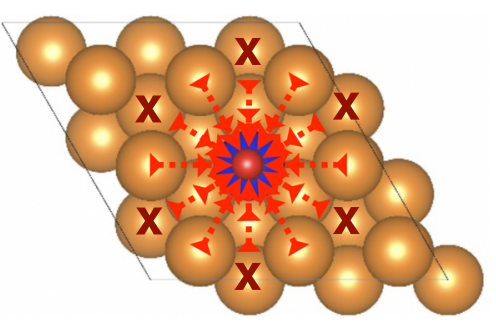

e

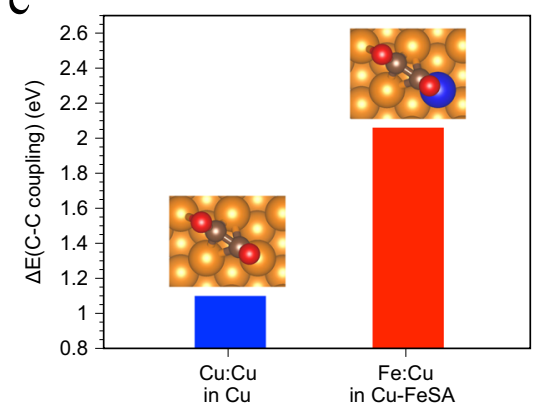

f

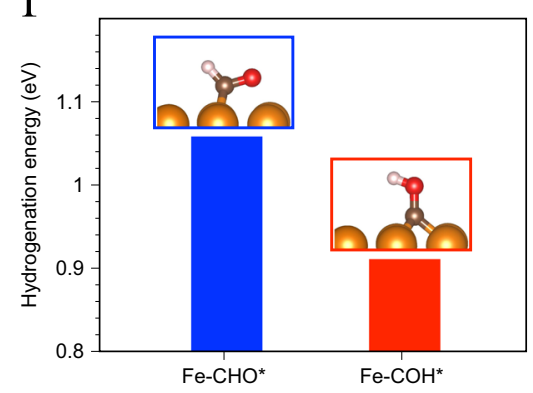

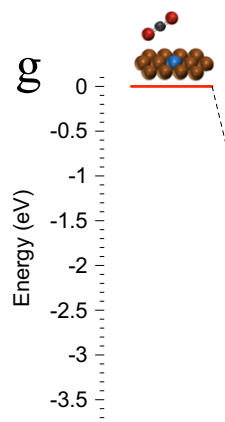
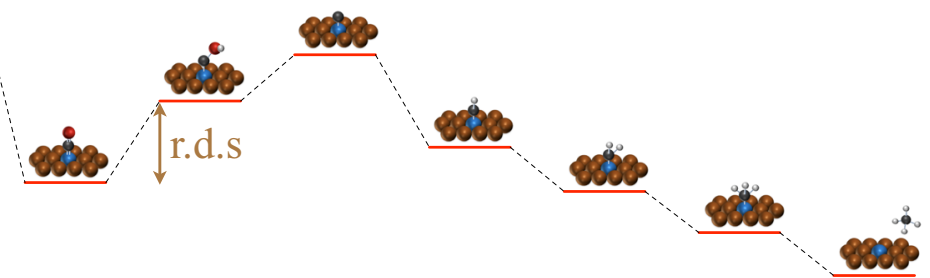

Fig. 2 Mechanism study for the copper-supported single-atom iron catalyst. a Density of states of pristine Cu and Cu-FeSA. b Adsorption energy of ${ }^{\star} \mathrm{CO}$ for pristine $\mathrm{Cu}$ and $\mathrm{Cu}-\mathrm{FeSA}$. c Deconvolution of $d$ orbitals of single-atom iron in Cu-FeSA. d Schematic illustration of ${ }^{\star} \mathrm{CO}$ transition: the arrow heads mean the transition pathway while the cross marks suggest immobile ${ }^{*} \mathrm{CO}$ adsorption sites. e C-C coupling energy for pristine $\mathrm{Cu}$ vs. $\mathrm{Cu}$-FeSA. $\mathbf{f} \mathrm{Hydrogenation}$ energy of the intermediates for methane production on the iron sites in Cu-FeSA. g Energy diagram for methane evolution in Cu-FeSA. The r.d.s. (rate determining step) is the hydrogenation of ${ }^{*} \mathrm{CO}$ intermediates on the iron sites.

iron was found (SEM, TEM and elemental scans over scales from nanometers to micrometers, Supplementary Figs. 25-29). The Fe proportion obtained using inductively coupled plasma mass spectrometry (ICP-MS) is 0.3 at $\%$.

In-situ Raman spectroscopy allows us to monitor materials synthesis and to identify reaction intermediates during $\mathrm{CO}_{2} \mathrm{RR}$. We first study the Raman spectra of bare $\mathrm{Cu}$ (Fig. 3f) as a reference. The initial faint peak at $520 \mathrm{~cm}^{-1}$ is ascribed to copper oxides, a mixture of $\mathrm{Cu}_{2} \mathrm{O}$ and $\mathrm{CuO}$ via $\mathrm{Cu}$ L-edge soft XAS (Supplementary Fig. 30), consistent with the XPS results in Supplementary Fig. 16. During $\mathrm{CO}_{2} \mathrm{RR}$, the surface oxides are reduced and $\mathrm{CO}$ intermediates are adsorbed on $\mathrm{Cu}\left({ }^{*} \mathrm{CO}_{\mathrm{Cu}}\right.$, $365 \mathrm{~cm}^{-1}$ for $\mathrm{Cu}-\mathrm{CO}$ stretch and $1079 \mathrm{~cm}^{-1}$ for $\mathrm{CO}_{3}{ }^{2-}$ symmetric stretch on $\mathrm{Cu}$ surface $)^{43-46}$. We also observe the intramolecular $\mathrm{C} \equiv \mathrm{O}$ stretch on the $\mathrm{Cu}$ surface (Supplementary Fig. 31).

In examining the in-situ Raman spectra of the precursor film $\mathrm{Cu}-\mathrm{FePc}$, we identified the peaks at $660 \mathrm{~cm}^{-1}, 745 \mathrm{~cm}^{-1}$, and $935 \mathrm{~cm}^{-1}$ as the phthalocyanine vibrations in $\mathrm{FePc}$, and the peak at $535 \mathrm{~cm}^{-1}$ as the ${ }^{*} \mathrm{CO}$ adsorbed on iron sites $\left({ }^{*} \mathrm{CO}\right.$ Fe, $\mathrm{Fe}-\mathrm{CO}$ stretch ${ }^{38,47-49}$. The Raman peaks of the phthalocyanine ring fade as the potential is decreased to $-1.1 \mathrm{~V}$ vs. RHE and further negative potentials, suggesting that the phthalocyanine ring has detached from the $\mathrm{Cu}$ surface, consistent with in-situ XAS results. The Fe-CO stretch remains after the removal of the phthalocyanine ring, confirming that the $\mathrm{Fe}$ atom is retained on the $\mathrm{Cu}$ surface. The intensity of ${ }^{*} \mathrm{CO}_{\mathrm{Fe}}$ is higher than that of ${ }^{*} \mathrm{CO}_{\mathrm{Cu}}$ in $\mathrm{Cu}-\mathrm{FeSA}$, agreeing with the view that $\mathrm{Fe}$ sites attract and convert $\mathrm{CO}_{2}$ to ${ }^{*} \mathrm{CO}$ on $\mathrm{Fe}$ sites, and suppress adsorbed ${ }^{*} \mathrm{CO}$ on $\mathrm{Cu}$ sites. In the case of $\mathrm{Cu}-\mathrm{FeSA}$, we observe a small intramolecular $\mathrm{C} \equiv \mathrm{O}$ stretch on the $\mathrm{Cu}$ surface under a low potential (Supplementary Fig. 31). This then vanishes under a high potential, and a new intramolecular $\mathrm{C} \equiv \mathrm{O}$ stretch on the $\mathrm{Fe}$ site appears. This observation is in agreement with the suppression of ${ }^{*} \mathrm{CO}$ on $\mathrm{Cu}$ sites. We associate the $740 \mathrm{~cm}^{-1}$ signal at $-0.6 \mathrm{~V}$ vs RHE with 3-MPA (Supplementary Fig. 32) since it is closed to the $\mathrm{Cu}$ surface. At $-0.7 \sim-1.0 \mathrm{~V}$ vs RHE, the noticeable red spots can be attributed to $\mathrm{FePc}$, which moves toward the copper surface and increases the Raman intensity as the 3-MPA detaches from the $\mathrm{Cu}$ surface. The intensity at $660 \mathrm{~cm}^{-1}$ and $935 \mathrm{~cm}^{-1}$ increases from $-0.6 \mathrm{~V}$ to $-0.7 \mathrm{~V}$ vs RHE and then decreases at a more negative voltage, suggesting that the phthalocyanine ring of $\mathrm{FePc}$ is detached from the $\mathrm{Cu}$ surface. We observe a signal associated with the 

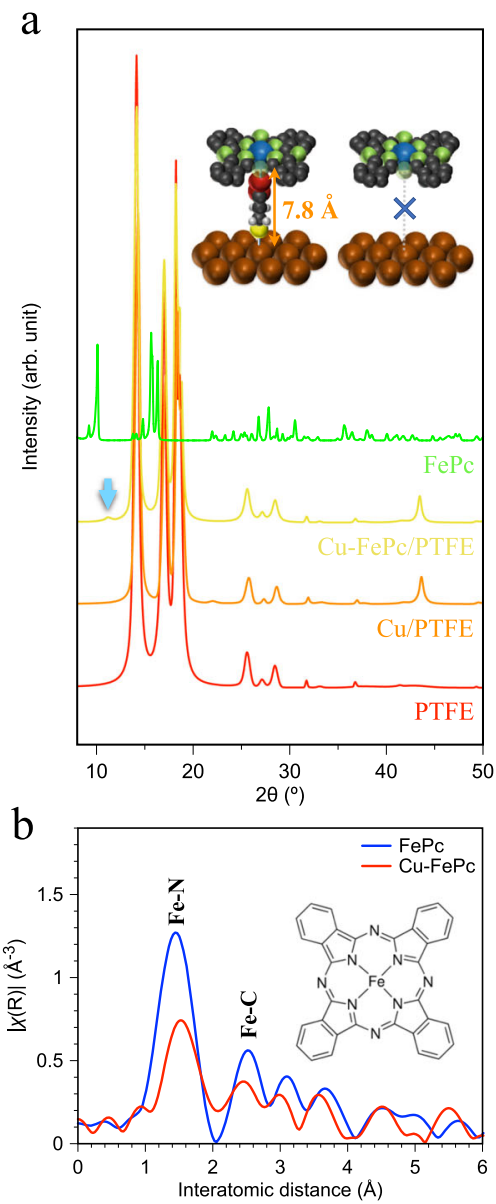

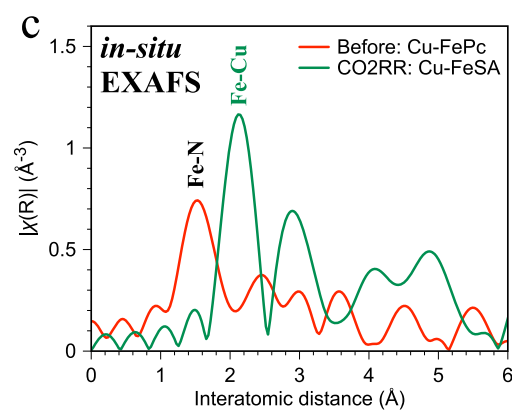

$\mathrm{d}$

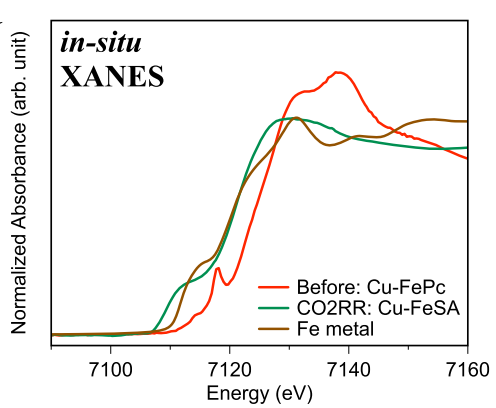

e
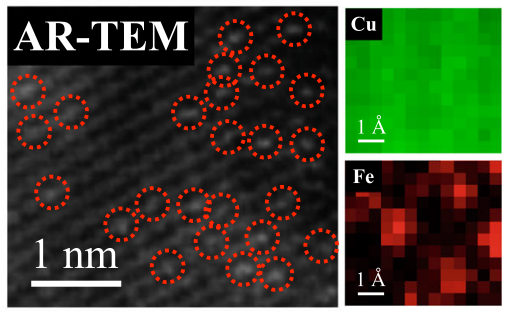
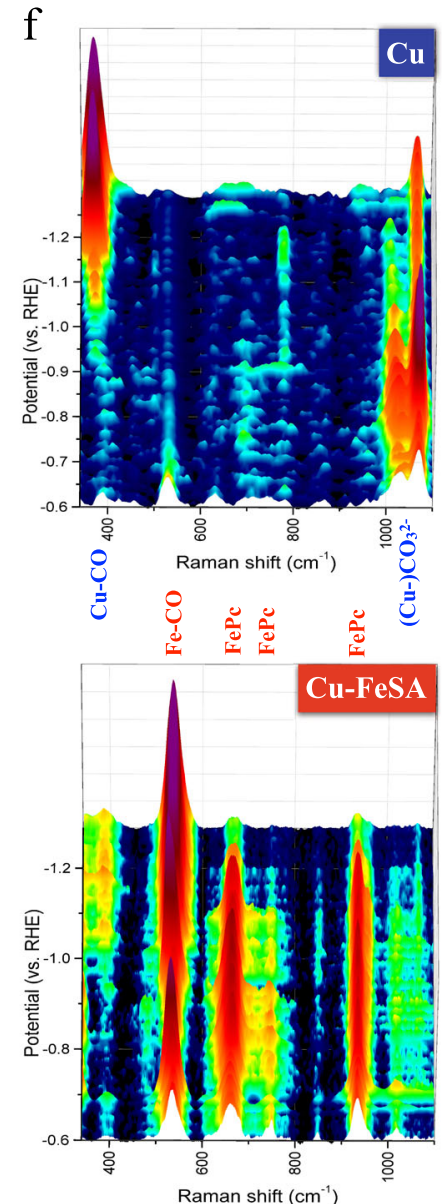

Fig. 3 Materials characterization and in-situ investigation of iron-phthalocyanine-modified and iron-single-atom-anchored copper. a $X$-ray diffraction. The inset illustrates the bonding between $\mathrm{Cu}$ surface and iron phthalocyanine using 3-mercaptopropionic acid. $\mathbf{b}$ Extended X-ray absorption fine structure (EXAFS) of Fe K-edge for the Cu-FePc GDE. c In-situ EXAFS and (d) in-situ XANES of Fe K-edge for identifying Cu-FeSA during $\mathrm{CO}_{2}$ RR. e Atomic resolution transmission electron microscope images and atomic elemental mapping using EELS. Dashed circles indicate the single-atom iron. $\mathbf{f}$ In-situ Raman spectroscopy for pristine $\mathrm{Cu}$ and $\mathrm{Cu}-\mathrm{FeSA}$. The intensity scale is 4000 c.p.s. in the spectrum.

phthalocyanine ligand that remains following $\mathrm{CO}_{2} \mathrm{RR}$, consistent with the view that iron atoms are attracted towards the copper surface and that some phthalocyanine rings remain near the copper surface, but they depart from the catalytic surface after approximately one hour. (Supplementary Fig. 33) Overall, we conclude that the Fe- $\mathrm{N}$ bond breaks during electrocatalysis, the phthalocyanine ring detaches from the central Fe ions, converting to $\mathrm{Cu}-\mathrm{FeSA}$. $\mathrm{Cu}-\mathrm{FeSA}$ shows strong adsorption of ${ }^{*} \mathrm{CO}$ on $\mathrm{Fe}$ sites following the reduction reaction.

We investigated $\mathrm{CO}_{2} \mathrm{RR}$ in neutral electrolyte $\left(1 \mathrm{M} \mathrm{KHCO}_{3}\right)$ in a flow cell. The neutral condition circumvents the consumption of $\mathrm{CO}_{2}$ by alkaline electroly $\mathrm{e}^{50}$, rendering it more compatible with sustained $\mathrm{CO}_{2} \mathrm{RR}$. The major product on the copper-supported iron-singleatom catalyst is methane, and its Faradaic efficiency (FE) reaches a maximum value of $64 \%$ at a current density of $200 \mathrm{~mA} \mathrm{~cm}^{-2}$ (Fig. 4a), showing progress in the direction of technoeconomic promise (Supplementary Table 2), while the nitrogen-dopedgraphene-supported one generates only carbon monoxide (Supplementary Fig. 34). In comparison, the major product on bare $\mathrm{Cu}$ is ethylene (maximum 54\% FE at a current density of $200 \mathrm{~mA} \mathrm{~cm}^{-2}$ ) and the methane $\mathrm{FE}$ is only $2 \% \mathrm{FE}$. The local $\mathrm{pH}$ in $\mathrm{KHCO}_{3}$ at $200 \mathrm{~mA} \mathrm{~cm}^{-2}$ is $12^{51}$. At high $\mathrm{pH}, \mathrm{C}-\mathrm{C}$ coupling dominates, and the $\mathrm{C} 1$ pathways are suppressed, facilitating selectivity to $\mathrm{C} 2$ products, in line with the catalytic result seen on bare $\mathrm{Cu}^{52} \cdot \mathrm{Cu}-\mathrm{FeSA}$ shows a $32 \mathrm{x}$ FE to methane compared to bare $\mathrm{Cu}$. The SAA system also gives a $1.3 \mathrm{x}$ higher $\mathrm{FE}$ to methane compared to the prior report ${ }^{53}$. We optimized catalytic performance by controlling several parameters: thickness of host copper layer, 3-MPA modification time, and FePc adsorption time (Supplementary Figs. 35-37). With optimal parameters, we achieved a methane partial current density of $128 \mathrm{~mA} \mathrm{~cm}^{-2}$ with a turnover frequency (TOF) of $31770 \mathrm{~h}^{-1}$, higher than $4.19 \mathrm{~h}^{-1}$ for bare Cu (Fig. 4b, Supplementary Note 1). The TOF of $\mathrm{Cu}-\mathrm{FeSA}$ for producing methane is higher than that of single-atom catalysts on nitrogen-doped carbon substrates for producing carbon monoxide $\left(14800 \mathrm{~h}^{-1}\right)^{3}$. When we added potassium thiocyanate into the catholyte to poison $\mathrm{Fe}^{54,55}$, methane selectivity dropped within several minutes: this suggests that the active site for the hydrogenation is Fe. Electrochemical impedance spectroscopy for Cu-FeSA (Supplementary Fig. 38) reveals a low $R_{C T}$ : the surface is therefore highly activated in the range of potential we apply ${ }^{56,57}$. We detect a small amount of ethylene $(2 \%)$ in Cu-FeSA (Supplementary Note 1 and Supplementary Figs. 39, 40).

The Cu-FeSA is stable during an electrolysis of $12 \mathrm{~h}$ : the methane FE and applied potential remain stable at a constant operating current density of $200 \mathrm{~mA} \mathrm{~cm}^{-2}$ (Fig. 4c). We offer that 
a

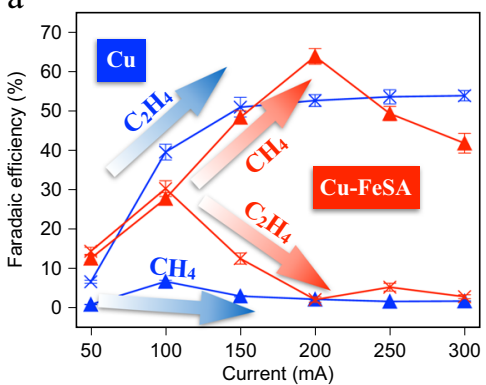

b

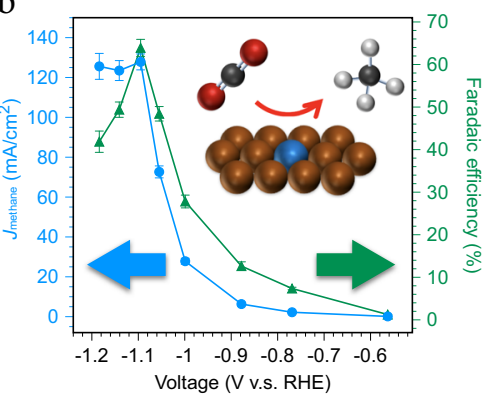

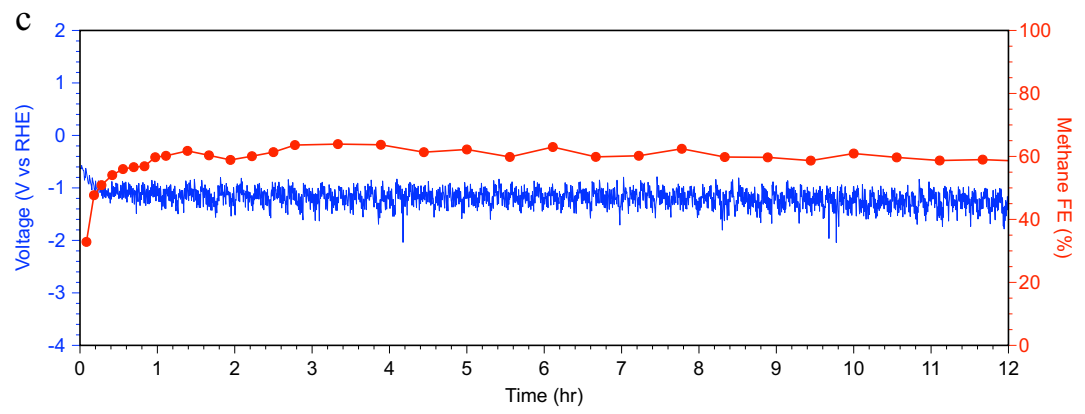

Fig. 4 Catalytic performance of Cu-FeSA. a Comparison of reaction products for pristine $\mathrm{Cu}$ and $\mathrm{Cu}$-FeSA. Error bars represent 1 standard deviation on the basis of three independent samples. b Faradaic efficiency and partial current density to methane vs. applied potential. c Stability of methane production. d In-situ X-ray absorption near-edge structure (XANES) of Fe K-edge for long-term investigation over $12 \mathrm{~h}$. The error bars represent $1 \mathrm{~s} . \mathrm{d}$. on the basis of three independent samples.

the activation process correlates with the fact that the phthalocyanine rings remain and then leave the catalytic surface, shown in Supplementary Fig. 33. We performed in-situ XAS to investigate the long-term evolution of electronic configurations of $\mathrm{Fe}$ (Fig. 4d). In-situ XANES provides oxidation number via analysis of the edge shift, and it provides the chemical orbital hybridization via the oscillation behavior near the white-light region. We did not observe an edge shift nor shape change near the whitelight region. This suggests that the chemical environment of $\mathrm{Cu}$ FeSA remains substantially unchanged during electromethanation. The Fe compositions, examined by ICP-MS, also remain similar before and after reaction. According to literature ${ }^{58,59}, \mathrm{Cu}$ undergoes dynamic phase transformation/surface reconstruction during $\mathrm{CO}_{2} \mathrm{RR}$, affecting catalytic stability. We performed in-situ time-resolved X-ray absorption spectroscopy (XAS) to investigate the relevant phenomenon, shown in Supplementary Fig. 41. The sputtered $\mathrm{Cu}$ in $\mathrm{Cu}-\mathrm{FeSA}$ exhibits a metallic state in $2 \mathrm{~min}$ and retains this over $30 \mathrm{~min}$. We did not observe dynamic reoxidation/reduction behavior and phase transformation reported previously in H-cell systems. In-situ Raman spectroscopy in Fig. $3 \mathrm{f}$ showed that the peak for surface copper oxide continuously decreases with increasing applied potential, without reoxidation. We conclude that, in the flow-cell system, the catalyst undergoes the intensive driving force of reduction at $200 \mathrm{~mA} \mathrm{~cm}^{-2}$, leading to undetectable reoxidation/reduction.

We developed $\mathrm{Cu}$-based catalysts containing Fe single atoms for the electrochemical methanation of $\mathrm{CO}_{2}$. We assembled $\mathrm{Fe}$ phthalocyanine onto the $\mathrm{Cu}$ surface and reduced it to $\mathrm{Fe}$ in a copper host during electrocatalysis. Fe attracts $\mathrm{CO}$ intermediates and contributes to their conversion through a $\mathrm{COH}$ intermediate to methane. We report $\mathrm{CO}_{2}$-to-methane conversion having a Faradaic efficiency of $64 \%$ and a partial current density of $128 \mathrm{~mA} \mathrm{~cm}^{-2}, 32$ times higher than $\mathrm{Cu}$ under the same conditions of electrolyte and bias. The more active single-atom $\mathrm{Fe}$ is present at the surface of the $\mathrm{Cu}$ and remains stable over the operating times considered herein.

\section{Methods}

Preparation of gas diffusion electrodes (GDEs). All chemicals were purchased from Sigma-Aldrich and used without further purification. GDE was made via deposition of sputtered $\mathrm{Cu}$ on a PTFE substrate, followed by assembly of iron phthalocyanine $(\mathrm{FePc})$ on the $\mathrm{Cu}$ surface. $\mathrm{Cu}$ with a thickness of $200 \mathrm{~nm}$ was sputtered on a PTFE substrate (pore size of $450 \mathrm{~nm}$ ) using a pure $\mathrm{Cu}$ target (99.99\%) with an $\mathrm{Ar}$ flow rate of 6 mtorr at an applied power of 85 Watts. Cu/PTFE was immersed in $10 \mathrm{mM} 3$-mercaptopropionic acid (3-MPA $\left.\mathrm{Aq}_{\mathrm{aq}}\right)$ for $10 \mathrm{~min}$ to modify the functional group on the copper surface, followed by a deionized water rinse and dried with nitrogen. Surface modified copper was submerged in $1 \mathrm{mM} \mathrm{FePc}(\mathrm{MeOH})$ for $90 \mathrm{~min}$, rinsed completely with methanol, and dried with nitrogen. The surface-modified substrate was soaked into $\mathrm{CoPc}_{(\mathrm{MeOH})}$ and $\mathrm{NiPc}_{(\mathrm{MeOH})}$ to obtain the $\mathrm{Cu}-\mathrm{CoPc}$ and $\mathrm{Cu}-\mathrm{NiPc}$. For Iron nanoparticles and clusters, $8.8 \mathrm{mg}$ of iron(II) chloride and $20 \mathrm{mg}$ of poly(methacrylic acid) ligand were added into a screw-neck glass bottle containing $5 \mathrm{ml}$ of methanol ${ }^{60}$. After the solution becoming uniform by sonication, $0.5 \mathrm{ml}$ of freshly prepared $\mathrm{NaBH}_{4}$ solution $\left(5 \mathrm{mg} \mathrm{ml}^{-1}\right.$ in methanol) was injected into the solution under vigorous stirring (2000 r.p.m.). The stirring speed of the solution was kept the same for another $10 \mathrm{~min}$. In the washing process, the precipitate was sonicated to ensure all clusters dispersing uniformly in methanol, and then separated by centrifuge.

Materials characterization. Microstructure and elemental analysis were collected by Hitachi SU5000 FE-SEM equipped Bruker energy dispersive X-ray spectroscopy. Cold-field emission Cs-corrected transmission electron microscope (JEOL ARM$200 \mathrm{~F}$ ) with $200 \mathrm{keV}$ acceleration voltage was used in microstructure analysis at Material and Chemical Laboratories, Industrial Technology Research Institute (ITRI), Taiwan. Electron Energy Loss Spectrum (EELS) observations were performed using Gatan Imaging Filter (GIF) model 965 QuantumER $^{\mathrm{ww}}$ at room temperature with camera length of $2 \mathrm{~cm}$. The energy resolution measured by the full width at half maximum of a zero-loss peak was about $0.4 \mathrm{eV}$ through a cold field emission gun. Surface morphology and step profile were measured using Veeco Dimension 5000 Scanning Probe Microscope (D5000) at Taiwan Semiconductor Research Institute (TSRI), Taiwan. Crystal structures were determined by X-ray diffraction (XRD) patterns, collected by Rigaku MiniFlex600 G6. The grazingincidence-angle XRD patterns were acquired by PANalytical X'Pert Pro at Taiwan Semiconductor Research Institute (TSRI), Taiwan. X-ray photoelectron spectroscopy (XPS) measurements were conducted on a Thermo Scientific K-Alpha spectrophotometer with a monochromated $\mathrm{Al} \mathrm{Ka}$ X-ray beam $(1486.60 \mathrm{eV})$. The depth-profiling XPS spectrum were collected on the same model at Taiwan Semiconductor Research Institute (TSRI), Taiwan. All binding energies of the elements were calibrated to adventitious carbon at $284.50 \mathrm{eV}$. X-ray absorption spectroscopy (XAS) including X-ray absorption near edge spectra (XANES) and extended X-ray absorption fine structure (EXAFS) of Fe K-edge were collected by a silicon drift detector at ambient air at the 9BM beamline of the Advanced Photon Source (APS) located at Argonne National Laboratory and at the SXRMB beamline 
of the Canadian Light Source (CLS). The pre-edge baseline was subtracted and the spectra was normalized to the post-edge. EXAFS analysis was conducted using a Fourier transform on $\mathrm{k}^{2}$-weighted EXAFS oscillations to evaluate the contribution of each bond pair to the Fourier transform peak. REX2000 software using ab initiocalculated phases and amplitudes from the program FEFF 8.2 was used for EXAFS fitting. $\mathrm{CN}, \mathrm{R}, \Delta \mathrm{E}$, and the EXAFS Debye-Waller factor (DW; $\sigma^{2}$ ) are variable parameters of the EXAFS equation for fitting the experimental result. XANES of $\mathrm{Cu}$ L-edge and Fe L-edge were obtained in total electron yield mode (TEY) and total fluorescence yield mode (TFY) at the SGM beamline of the Canadian Light Source (CLS). The iron concentration was quantified by inductively coupled plasma mass spectrometry (ICP-MS).

Electrocatalytic characterization. Electrochemical properties were investigated using an Autolab PGSTAT204 potentiostat in a flow cell reactor using a gas diffusion electrode (GDE) as the working electrode (WE), nickel foam as the counter electrode (CE) and a saturated $\mathrm{Ag} / \mathrm{AgCl}$ electrode as the reference electrode (RE). The WE and CE were separated by an anion exchange membrane. Aqueous solution of $1.0 \mathrm{M} \mathrm{KHCO}_{3}$ saturated with $\mathrm{CO}_{2}(\mathrm{pH}=7.0)$ was used as the electrolyte and the flow rate of $\mathrm{CO}_{2}$ was $50 \mathrm{sccm}$. The potentials were converted to values relative to RHE based on the following equation: $\mathrm{E}_{\mathrm{RHE}}=\mathrm{E}_{\mathrm{Ag} / \mathrm{AgCl}}+0.0591 \times \mathrm{pH}+\mathrm{E}_{\mathrm{Ag} / \mathrm{AgCl}}^{0}$ where $\mathrm{E}^{0} \mathrm{Ag} / \mathrm{AgCl}$ is the standard potential of $\mathrm{Ag} / \mathrm{AgCl}$ relative to SHE at $25^{\circ} \mathrm{C}$ $(0.210 \mathrm{~V})$. The working area of electrodes was $1.0 \mathrm{~cm}^{2}$ for each experiment. Linear sweep voltammetry was performed at the scan rate of $20 \mathrm{mV} / \mathrm{s}$ with iR-correction. Rs and Nyquist plot were collected by electrochemical impedance spectroscopy (EIS) measurements with a frequency range from 0.1 to $10^{5} \mathrm{~Hz}$ with $\mathrm{AC}$ amplitude of $10 \mathrm{mV}$. Cyclic voltammetry was measured at the scan rate of $100 \mathrm{mV} / \mathrm{s}$. The gaseous products were evaluated via gas chromatography (PerkinElmer Clarus 600) equipped with a thermal conductivity detector and a flame ionization detector. TOFs $\left(h^{-1}\right)$ for the $\mathrm{CO}_{2} \mathrm{RR}$ were evaluated based on the 8-electron pathway for methane. $\mathrm{TOF}=$ Turnover number for methane formation/Number of active sites. The iron poisoning experiment was conducted by adding $0.01 \mathrm{M}$ potassium thiocyanate into the catholyte after the single-atom iron formed during $\mathrm{CO}_{2} \mathrm{RR}$.

In-situ identification. We executed in-situ X-ray absorption spectroscopy in the same conditions as electrochemical testing using a customized flow cell with an opening sealed by Kepton tape in the gas chamber. We collected the XAS signal using a Vortex detector at the 9BM beamline of the Advanced Photon Source (APS). We conducted in-situ time-resolved XAS at the 44A beamline of the Taiwan Photon Source (TPS, NSRRC, Taiwan). In-situ Raman measurements were conducted using a Renishaw inVia Raman microscope in a modified flow cell with a water immersion objective, employing a diode laser at $785 \mathrm{~nm} . \mathrm{CO}_{2}$ with a flow rate of $40 \mathrm{sccm}$ flowed through the gas chamber. $\mathrm{An} \mathrm{Ag} / \mathrm{AgCl}(3 \mathrm{M} \mathrm{KCl})$ electrode and a $\mathrm{Pt}$ wire were used as the reference and counter electrodes, respectively, for the insitu Raman measurements.

Theoretical calculations. We performed Density functional theory calculations with the Vienna Ab Initio Simulation Package (VASP) code $^{61,62}$. The exchange correlation energy was modeled by using Perdew-Burke-Ernzerhof (PBE) functional within the generalized gradient approximation $(\mathrm{GGA})^{63}$. The projector augmented wave (PAW) pseudo-potentials ${ }^{64}$ were used to describe ionic cores. The cutoff energy of $450 \mathrm{eV}$ was adopted after a series of tests. A Methfessel-Paxton smearing of $0.05 \mathrm{eV}$ to the orbital occupation is applied during the geometry optimization and for the total energy computations. In all calculations, the atoms at all positions have Hellmann-Feynman forces lower than $0.02 \mathrm{eV} \AA^{-1}$ and the electronic iterations convergence was $10^{-5} \mathrm{eV}$ using the Normal algorithm. A 6-layer $(4 \times 4) \mathrm{Cu}(111)$ supercell was built to simulate the exposed surface of copper accompanying with a sufficient vacuum gap of $15 \AA$. Iron atom was exposed on the surface by replacing a $\mathrm{Cu}$ atom. Structural optimizations were performed on all modified slab models with a grid of $(3 \times 3 \times 1) \mathrm{k}$-point. During the adsorption calculations, the top three layers are fully relaxed while the other layers are fixed at the tested lattice positions. The detailed model was referred to Supplementary Note 2.

\section{Data availability}

The data supporting this study are available within the paper and the Supplementary Information. All other relevant source data are available from the corresponding authors upon reasonable request.

Received: 14 March 2021; Accepted: 27 January 2022;

Published online: 10 February 2022

\section{References}

1. Bartholomew, C. H. \& Farrauto, R. J. Fundamentals of Industrial Catalytic Processes. 8 (John Wiley and Sons, Inc., 2006).

2. Yang, X.-F. et al. Single-atom catalysts: a new frontier in heterogeneous catalysis. Acc. Chem. Res. 46, 1740-1748 (2013).

3. Yang, H. B. et al. Atomically dispersed $\mathrm{Ni}(\mathrm{i})$ as the active site for electrochemical $\mathrm{CO}_{2}$ reduction. Nat. Energy 3, 140-147 (2018).
4. Chen, Y. et al. Atomic Fe Dispersed on N-Doped carbon hollow nanospheres for high-efficiency electrocatalytic oxygen reduction. Adv. Mater. 31, 1806312 (2019)

5. Gu, J., Hsu, C.-S., Bai, L., Chen, H. M. \& Hu, X. Atomically dispersed Fe3+ sites catalyze efficient $\mathrm{CO}_{2}$ electroreduction to CO. Science 364, 1091-1094 (2019).

6. Zhang, $\mathrm{H}$. et al. A graphene-supported single-atom $\mathrm{FeN}_{5}$ catalytic site for efficient electrochemical $\mathrm{CO}_{2}$ reduction. Angew. Chem. Int. Ed. 58, 14871-14876 (2019)

7. Gao, J. et al. Enabling direct $\mathrm{H}_{2} \mathrm{O}_{2}$ production in acidic media through rational design of transition metal single atom catalyst. Chem 6, 658-674 (2020).

8. Zhang, $H$. et al. Single atomic iron catalysts for oxygen reduction in acidic media: particle size control and thermal activation. J. Am. Chem. Soc. 139, 14143-14149 (2017).

9. Jiao, L. et al. From metal-organic frameworks to single-atom Fe Implanted $\mathrm{N}$-doped porous carbons: efficient oxygen reduction in both alkaline and acidic media. Angew. Chem. Int. Ed. 57, 8525-8529 (2018).

10. Hori, Y., Wakebe, H., Tsukamoto, T. \& Koga, O. Electrocatalytic process of $\mathrm{CO}$ selectivity in electrochemical reduction of $\mathrm{CO}_{2}$ at metal electrodes in aqueous media. Electrochim. Acta 39, 1833-1839 (1994).

11. Su, X., Yang, X. F., Huang, Y., Liu, B. \& Zhang, T. Single-atom catalysis toward efficient $\mathrm{CO}_{2}$ conversion to $\mathrm{CO}$ and formate products. Acc. Chem. Res. 52, 656-664 (2019).

12. Ju, W. et al. Understanding activity and selectivity of metal-nitrogen-doped carbon catalysts for electrochemical reduction of $\mathrm{CO}_{2}$. Nat. Commun. 8, 944 (2017).

13. Varela, A. S., Ju, W. \& Strasser, P. Molecular nitrogen-carbon catalysts, solid metal organic framework catalysts, and solid metal/nitrogen-doped carbon (MNC) catalysts for the electrochemical $\mathrm{CO}_{2}$ reduction. Adv. Energy Mater. 8, 1703614 (2018).

14. Ren, W. et al. Isolated diatomic Ni-Fe metal-nitrogen sites for synergistic electroreduction of $\mathrm{CO}_{2}$. Angew. Chem. Int. Ed. 58, 6972-6976 (2019).

15. Darby, M. T., Stamatakis, M., Michaelides, A. \& Sykes, E. C. H. Lonely atoms with special gifts: breaking linear scaling relationships in heterogeneous catalysis with single-atom alloys. J. Phys. Chem. Lett. 9, 5636-5646 (2018).

16. Darby, M. T., Réocreux, R., Sykes, E. C. H., Michaelides, A. \& Stamatakis, M. Elucidating the stability and reactivity of surface intermediates on single-atom alloy catalysts. ACS Catal. 8, 5038-5050 (2018)

17. Cheng, M.-J., Clark, E. L., Pham, H. H., Bell, A. T. \& Head-Gordon, M. Quantum mechanical screening of single-atom bimetallic alloys for the selective reduction of $\mathrm{CO}_{2}$ to $\mathrm{C} 1$ hydrocarbons. ACS Catal. 6, 7769-7777 (2016).

18. Dresselhaus, M. S. \& Thomas, I. L. Alternative energy technologies. Nature 414, 332-337 (2001).

19. Chu, S. \& Majumdar, A. Opportunities and challenges for a sustainable energy future. Nature 488, 294-303 (2012).

20. Seh, Z. W. et al. Combining theory and experiment in electrocatalysis: insights into materials design. Science 355, eaad4998 (2017).

21. Birdja, Y. Y. et al. Advances and challenges in understanding the electrocatalytic conversion of carbon dioxide to fuels. Nat. Energy 4, 732-745 (2019).

22. Handoko, A. D., Wei, F., Jenndy, Yeo, B. S. \& Seh, Z. W. Understanding heterogeneous electrocatalytic carbon dioxide reduction through operando techniques. Nat. Catal. 1, 922-934 (2018).

23. Liu, X. et al. $\mathrm{pH}$ effects on the electrochemical reduction of $\mathrm{CO}_{2}$ towards $\mathrm{C} 2$ products on stepped copper. Nat. Commun. 10, 32 (2019).

24. Zheng, Y. et al. Understanding the roadmap for electrochemical reduction of $\mathrm{CO}_{2}$ to multi-carbon oxygenates and hydrocarbons on copper-based catalysts. J. Am. Chem. Soc. 141, 7646-7659 (2019).

25. Manthiram, K., Beberwyck, B. J. \& Alivisatos, A. P. Enhanced electrochemical methanation of carbon dioxide with a dispersible nanoscale copper catalyst. J. Am. Chem. Soc. 136, 13319-13325 (2014).

26. Reske, R., Mistry, H., Behafarid, F., Roldan Cuenya, B. \& Strasser, P. Particle size effects in the catalytic electroreduction of $\mathrm{CO}_{2}$ on $\mathrm{Cu}$ nanoparticles. J. Am. Chem. Soc. 136, 6978-6986 (2014).

27. $\mathrm{Li}, \mathrm{Y}$. et al. Structure-sensitive $\mathrm{CO}_{2}$ electroreduction to hydrocarbons on ultrathin 5-fold twinned copper nanowires. Nano Lett. 17, 1312-1317 (2017)

28. Jouny, M., Luc, W. \& Jiao, F. General techno-economic analysis of $\mathrm{CO}_{2}$ electrolysis systems. Ind. Eng. Chem. Res. 57, 2165-2177 (2018).

29. Hung, S.-F. Electrochemical flow systems enable renewable energy industrial chain of $\mathrm{CO}_{2}$ reduction. Pure Appl. Chem. 92, 1937-1951 (2020).

30. Zhou, B. et al. Highly efficient binary copper-iron catalyst for photoelectrochemical carbon dioxide reduction toward methane. Proc. Natl. Acad. Sci. USA 117,1330-1338 (2020).

31. Norskov, J. K., Abild-Pedersen, F., Studt, F. \& Bligaard, T. Density functional theory in surface chemistry and catalysis. Proc. Natl Acad. Sci. USA 108, 937-943 (2011). 
32. Elahifard, M., Fazeli, E., Joshani, A. \& Gholami, M. Ab-Initio calculations of the $\mathrm{CO}$ adsorption and dissociation on substitutional $\mathrm{Fe}-\mathrm{Cu}$ surface alloys relevant to Fischer-Tropsch Synthesis: bcc- $(\mathrm{Cu}) \mathrm{Fe}(100)$ and fcc- $(\mathrm{Fe}) \mathrm{Cu}(100)$. Surf. Interface Anal. 45, 1081-1087 (2013).

33. Huang, Y., Handoko, A. D., Hirunsit, P. \& Yeo, B. S. Electrochemical reduction of $\mathrm{CO}_{2}$ using copper single-crystal surfaces: effects of $\mathrm{CO}^{*}$ coverage on the selective formation of ethylene. ACS Catal. 7, 1749-1756 (2017).

34. $\mathrm{Li}, \mathrm{J}$. et al. Constraining CO coverage on copper promotes high-efficiency ethylene electroproduction. Nat. Catal. 2, 1124-1131 (2019).

35. Hiraike, Y. et al. Active site formation mechanism of carbon-based oxygen reduction catalysts derived from a hyperbranched iron phthalocyanine polymer. Nanoscale Res. Lett. 10, 179 (2015).

36. Krylova, V., Andrulevičius, M. Optical, XPS and XRD Studies of Semiconducting Copper Sulfide Layers on a Polyamide Film. Int. J. Photoenergy 2009, 304308 (2009).

37. Wang, Y., Im, J., Soares, J. W., Steeves, D. M. \& Whitten, J. E. Thiol adsorption on and reduction of copper oxide particles and surfaces. Langmuir 32, 3848-3857 (2016).

38. Chen, Z. et al. Operando characterization of iron phthalocyanine deactivation during oxygen reduction reaction using electrochemical tip-enhanced raman spectroscopy. J. Am. Chem. Soc. 141, 15684-15692 (2019).

39. Hung, S.-F. In-situ X-ray techniques for non-noble electrocatalysts. Pure Appl. Chem. 92, 733-749 (2020).

40. Geisler, B. \& Kratzer, P. Adsorption and dissociation of iron phthalocyanine on $\mathrm{H} / \mathrm{Si}(111)$ : impact of van der Waals interactions and perspectives for subsurface doping. Phys. Rev. B 99, 155433 (2019).

41. Isvoranu, C. et al. Pyridine adsorption on single-layer iron phthalocyanine on $\mathrm{Au}(111)$. J. Phys. Chem. C. 115, 20201-20208 (2011).

42. Snezhkova, O. et al. Iron phthalocyanine on $\mathrm{Cu}(111)$ : coverage-dependent assembly and symmetry breaking, temperature-induced homocoupling, and modification of the adsorbate-surface interaction by annealing. J. Chem. Phys. 144, 094702 (2016).

43. Oda, I., Ogasawara, H. \& Ito, M. Carbon monoxide adsorption on copper and silver electrodes during carbon dioxide electroreduction studied by infrared reflection absorption spectroscopy and surface-enhanced raman spectroscopy. Langmuir 12, 1094-1097 (1996).

44. Deng, Y. \& Yeo, B. S. Characterization of electrocatalytic water splitting and $\mathrm{CO}_{2}$ reduction reactions using in situ/operando Raman Spectroscopy. ACS Catal. 7, 7873-7889 (2017).

45. Chernyshova, I. V., Somasundaran, P. \& Ponnurangam, S. On the origin of the elusive first intermediate of $\mathrm{CO}_{2}$ electroreduction. Proc. Natl Acad. Sci. USA 115, E9261 (2018).

46. Jiang, S., Klingan, K., Pasquini, C. \& Dau, H. New aspects of operando Raman spectroscopy applied to electrochemical $\mathrm{CO}_{2}$ reduction on $\mathrm{Cu}$ foams. J. Chem. Phys. 150, 041718 (2019).

47. Uno, T. et al. The resonance Raman frequencies of the Fe-CO stretching and bending modes in the CO complex of cytochrome P-450cam. J. Biol. Chem. 260, 2023-2026 (1985).

48. Palys, B. J., van den Ham, D. M. W., Briels, W. \& Feil, D. Resonance Raman spectra of phthalocyanine monolayers on different supports. A normal mode analysis of zinc phthalocyanine by means of the MNDO method. J. Raman Spectrosc. 26, 63-76 (1995).

49. Hines, J. P. et al. CO and NO bind to Fe(II) DiGeorge critical region 8 heme but do not restore primary microRNA processing activity. J. Biol. Inorg. Chem. 21, 1021-1035 (2016).

50. Weekes, D. M., Salvatore, D. A., Reyes, A., Huang, A. \& Berlinguette, C. P. Electrolytic $\mathrm{CO}_{2}$ reduction in a flow cell. Acc. Chem. Res. 51, 910-918 (2018).

51. Li, F. et al. Molecular tuning of $\mathrm{CO}_{2}$-to-ethylene conversion. Nature 577, 509-513 (2020).

52. Xiao, H., Cheng, T., Goddard, W. A. \& Sundararaman, R. Mechanistic explanation of the $\mathrm{pH}$ dependence and onset potentials for hydrocarbon products from electrochemical reduction of $\mathrm{CO}$ on $\mathrm{Cu}$ (111). J. Am. Chem. Soc. 138, 483-486 (2016).

53. Wang, X. et al. Efficient methane electrosynthesis enabled by tuning local $\mathrm{CO}_{2}$ availability. J. Am. Chem. Soc. 142, 3525-3531 (2020).

54. Chen, Y. et al. Enhanced oxygen reduction with single-atomic-site iron catalysts for a zinc-air battery and hydrogen-air fuel cell. Nat. Commun. 9, 5422 (2018).

55. Ren, G. et al. Ancient Chemistry "Pharaoh's Snakes" for efficient Fe-/N-Doped carbon electrocatalysts. ACS Appl. Mater. Inter. 10, 10778-10785 (2018).

56. Shah, A. H. et al. Revisiting electrochemical reduction of $\mathrm{CO}_{2}$ on $\mathrm{Cu}$ electrode: where do we stand about the intermediates? J. Phys. Chem. C. 122, 18528-18536 (2018).

57. Liu, K. et al. Electronic effects determine the selectivity of planar $\mathrm{Au}-\mathrm{Cu}$ bimetallic thin films for electrochemical $\mathrm{CO}_{2}$ reduction. ACS Appl. Mater Inter. 11, 16546-16555 (2019).
58. Chang, C.-J. et al. Quantitatively unraveling the redox shuttle of spontaneous oxidation/electroreduction of $\mathrm{CuOx}$ on silver nanowires using in situ X-ray absorption spectroscopy. ACS Cent. Sci. 5, 1998-2009 (2019).

59. Chang, C.-J. et al. Dynamic reoxidation/reduction-driven atomic interdiffusion for highly selective $\mathrm{CO}_{2}$ reduction toward methane. J. Am. Chem. Soc. 142, 12119-12132 (2020).

60. Li, Y. H. et al. Unidirectional suppression of hydrogen oxidation on oxidized platinum clusters. Nat. Commun. 4, 2500 (2013).

61. Kresse, G. \& Hafner, J. Ab initio molecular-dynamics simulation of the liquidmetal-amorphous-semiconductor transition in Germanium. Phys. Rev. B 49, 14251-14269 (1994).

62. Kresse, G. \& Furthmüller, J. Efficient iterative schemes for ab initio totalenergy calculations using a plane-wave basis set. Phys. Rev. B 54, 11169-11186 (1996).

63. Perdew, J. P., Burke, K. \& Ernzerhof, M. Generalized gradient approximation made simple. Phys. Rev. Lett. 77, 3865-3868 (1996).

64. Kresse, G. \& Joubert, D. From ultrasoft pseudopotentials to the projector augmented-wave method. Phys. Rev. B 59, 1758-1775 (1999).

\section{Acknowledgements}

The authors acknowledge funding support from Natural Gas Innovation Fund, the Natural Sciences and Engineering Research Council (NSERC) of Canada, and Natural Resources Canada Clean Growth Program, and Ontario Research Fund - Research Excellence program. All DFT computations were performed on the Niagara supercomputer at the SciNet HPC Consortium. SciNet is funded by the Canada Foundation for Innovation, the Government of Ontario, Ontario Research Fund Research Excellence Program, and the University of Toronto. The authors thank T. Wu and G. Sterbinsky for technical support at the 9BM beamline of the Advanced Photon Source (Lemont, IL). This research used resources of the Advanced Photon Source, an Office of Science User Facility operated for the US Department of Energy (DOE) Office of Science by Argonne National Laboratory and was supported by the US DOE under Contract no. DE-AC02-06CH11357, and the Canadian Light Source and its funding partners. The authors thank Y. Hu, Q. Xiao, M. Shakouri at the 06B1-1 (SXRMB) beamline, and T. Regier and J. Dynes at the 11ID-1 (SGM) at the Canadian Light Source for their technical support. The authors also thank the help from Material and Chemical Laboratories, Industrial Technology Research Institute (ITRI), Taiwan, for STEM/EELS observation and FIB sample preparation. Dr. Mu Tung Chang and Dr. Ren-Fong Cai are responsible for acquiring HADDF STEM atomic image as well as the EELS spectrum analysis. Dr. Shih-Yi Liu and Ms. Mei Lun Wu are responsible to prepare plane-view TEM sample and sample pretreatment before FIB. S.-F.H. acknowledges support from Postdoctoral Research Abroad Program, Ministry of Science and Technology, Taiwan (Contract No. MOST 108-2917-I-564-016, MOST 110-2113-M-009-007-MY2 and MOST 110-2628-M-A49-002) and from the Yushan Young Scholar Program, Ministry of Education, Taiwan.

\section{Author contributions}

E.H.S. supervised the project. S-F.H. conceived the idea and carried out the experiments. S-F.H. and E.H.S. wrote the paper. A.X. carried out the DFT calculations. X.W. and F.L. conducted the in-situ Raman measurements. S-F.H. performed the in-situ XAS measurements. S.-H.H. conducted and analyzed the AFM, depth-profiling XPS, and grazing incidence-angle XRD. Y.L. and E.G.C. carried out part of electrochemical experiments. A.S.R. conducted the XPS measurement. X.W., F.L., Y.C.L., M.L., J.W., D.-H.N., and N.W. assisted in data analysis and manuscript writing. T.P., Y.Y., and G.L. helped to characterize the materials. All authors discussed the results and assisted during manuscript preparation.

\section{Competing interests}

The authors declare no competing interests.

\section{Additional information}

Supplementary information The online version contains supplementary material available at https://doi.org/10.1038/s41467-022-28456-9.

Correspondence and requests for materials should be addressed to Edward H. Sargent.

Peer review information Nature Communications thanks Yafei Li and the other anonymous reviewer(s) for their contribution to the peer review of this work. Peer reviewer reports are available.

Reprints and permission information is available at http://www.nature.com/reprints

Publisher's note Springer Nature remains neutral with regard to jurisdictional claims in published maps and institutional affiliations. 
(c) (i) Open Access This article is licensed under a Creative Commons Attribution 4.0 International License, which permits use, sharing, adaptation, distribution and reproduction in any medium or format, as long as you give appropriate credit to the original author(s) and the source, provide a link to the Creative Commons license, and indicate if changes were made. The images or other third party material in this article are included in the article's Creative Commons license, unless indicated otherwise in a credit line to the material. If material is not included in the article's Creative Commons license and your intended use is not permitted by statutory regulation or exceeds the permitted use, you will need to obtain permission directly from the copyright holder. To view a copy of this license, visit http://creativecommons.org/ licenses/by/4.0/.

(C) The Author(s) 2022 